\title{
GOOD TEACHING AND GOOD PERFORMANCE" REQUIRES THE ESTABLISHMENT OF REFERENCE - TEACHING REFORMS IN HIGHER EDUCATION
}

\author{
Prof. Dr VJOLLCA HASANI ${ }^{1}$ \\ PHD ○ KUMRIJE GAGICA ${ }^{2}$ \\ Prof. Dr ALBA DUMI ${ }^{3}$
}

Pristina Univrsity, Tirana University,

\begin{abstract}
Evaluation of teacher performance can also be used to determine career advancement, award performance rewards or establish sanctions for underperforming teachers. It constitutes an opportunity to recognize and reward teaching competence and performance, which is essential to retain effective teachers in schools as well as to make teaching an attractive career choice. (OECD, 2005)

In general, teacher evaluation frameworks might have consequences at the following levels: Career advancement. Most countries do not link directly teacher evaluation results with teacher $\bullet$ pay but, instead, to career progression (therefore establishing an indirect link with salaries). An example is England where teachers who meet the standards for "Post Threshold, Excellent and Advanced Skills Teachers" also access the higher pay scale.

Most teacher evaluation models relate results to the speed at which the teacher progresses in the career. Typically, ratings in the top categories of the rating scale make the teacher progress faster in the career scale while ratings in the bottom categories of the rating scale led to no career progression during the period associated with the evaluation.

Establishing effective teacher evaluation procedures is challenging at several levels: accuracy of the measurement, inclusion of all the dimensions of what is meant to be measured, consistency with the goals of the feedback exercise, adaptation to the needs of those who will use the results (teachers, school leaders, educational authorities), cost-effectiveness, and practical feasibility. Teacher evaluation requires the establishment of reference standards and evaluation criteria to allow proper assessments of performance to be made.
\end{abstract}

JEL Classification Security System: N0, N1, N2, N3, O1, O2, 03.

\section{INTRODUCTION}

The reform is aiming to identify and support HEIs which will strive for the status of "research universities", in order to enter the group of best European and World HEIs. The HEIs will be identified on a basis of an open competition and will be obliged to present a plan of developing and increasing quality of their research activities and quality of teaching which will contribute to the future improvement of HEI's position on the international research market. In order to implement this plan selected HEIs will receive higher funding in the years 20202026. HEIs applying for additional funding will have to present an application including e.g., analysis of their own potential and research development plans, in particular related to:

1. better contribution towards development of global research,

2. strengthening of research cooperation with research institution with high position on the international scale,

3. improvement in the quality of teaching of students and doctoral students,

4. improvements of HEIs' staff policy,

5. Improvement in the quality of management of HEIs. 
In particular, a definition of what, good $^{\text {ee }}$ teaching is needs to be developed. Performance measurement also calls for a judicious choice of instruments and sources of information. For instance, using student results to evaluate individual teachers is particularly challenging since learning outcomes are the result of a multitude of factors including the students ${ }^{\text {ee }}$ socio-economic background. Teachers have specific needs for feedback, and therefore evaluation procedures need to be designed to meet those needs. Improving teacher evaluation effectiveness implies choosing adequate procedures for given objectives (e.g., internal vs. external process; formative vs. summative process). The following three key aspects are analyzed in turn: Character and nature of teacher evaluation

\section{GENERAL INFORMATION AND PURPOSE OF THIS PAPER RESEARCH:}

A key objective of teacher evaluation is to identify areas of improvement for individual teachers, leading to the preparation of individual improvement plans (including professional development) which take into account the overall school development plan. Without a link to professional development opportunities, the evaluation process is not sufficient to improve teacher performance, and as a result, often become a meaningless exercise that encounters mistrust - or at best apathy - on the part of teachers being evaluated

Typically, schools are provided with autonomy to determine how teacher evaluation results feed into teacher professional and school development plans. School pedagogical leadership plays the key role in ensuring the effectiveness of such link (Pont et al., 2008). Another key element are the resources made available for professional and school development. Teacher evaluation might be mostly externally-driven or primarily internally-based (or school-based). In the former case, aspects assessed, instruments used as well as evaluation criteria are common across schools and evaluators are predominantly external to the school of the assessed teacher. In the latter case, the school takes responsibility for designing specific evaluation criteria and instruments, following-up evaluation results and evaluators are mostly internal to the school. (Godberg S, 2006)

1. Teacher evaluation can be carried out at regular intervals (e.g., every two years), at key stages of the career (e.g. for promotion within the career), or on specific occasions such as at the end of the probationary period or for contract renewal for contract teachers. School-based teacher evaluation vs. externally-driven teacher evaluation (OECD, 2005).

Teacher evaluation which is mostly internal to the school has the advantage of giving the school ownership of the evaluation processes and ensuring that all aspects are carefully considered by the school. (Donnin A,2009)

It also ensures that the school context is taken into account - the individual teacher is evaluated against reference standards with criteria that account for her school's objectives and socio-educational background. (Adel E)

1. Also, the use of internally devised instruments is in principle more appropriate for teacher evaluation for improvement. In terms of evaluation for accountability, however, there might be a case for using a national framework and standard procedures in the case the consequences of such teacher evaluation are at the national level and there is a risk that standards might differ across schools. (OECD, 2005).

\section{Reference standards, aspects evaluated and evaluation criteria}

1. Reference standards: A fair and reliable teacher evaluation model needs reference standards to evaluate teachers relatively to what is considered as ,goodee teaching. (OECD, 2005).

Teaching competences and responsibilities should be listed in order to build a comprehensive definition of what teachers should know and be able to do in the exercise of their profession.

The main reference standards for teacher evaluation typically are: Review on Evaluation and Assessment Frameworks for Improving School Outcomes Teacher professional profiles (general profile of competencies for teachers), including specialized profiles for particular types of teachers (e.g., level of education, subject).

2. Set of general and professional duties of teachers, including job descriptions.

3. At the level of the school, school development plan, the internal regulation and the annual activity plan. 
4. The key element is the teacher professional profile, a clear and concise statement of what teachers are expected to know and be able to do.

5. A fundamental precondition for the preparation of a profile of teacher competencies is a clear statement of objectives for student learning. Teachers ${ }^{\text {ee }}$ work and the knowledge and skills that they need to be effective must reflect the student learning objectives that schools are aiming to achieve.

6. There needs to be profession-wide standards and a shared understanding of what counts as accomplished teaching (OECD, 2005).

7. Teacher profiles often express different levels of performance appropriate to beginning teachers, experienced teachers, and those with higher responsibilities.

8. It is important to note that professional profiles provide the common basis to organize the key elements of the teaching profession such as initial teacher education, teacher certification (e.g. the entry exams), teachers ${ }^{\text {ee }}$ ongoing professional development, career advancement and, of course, teacher evaluation

Criteria for an Effective Teacher Evaluation System

Teacher evaluation should be based on professional teaching standards and should be sophisticated enough to assess teaching quality across the continuum of development from novice to expert teacher.

H1. Evaluations should include multi-faceted evidence of teacher practice, student learning, and professional contributions that are considered in an integrated fashion, in relation to one another and to the teaching context. Any assessments used to make judgments about students' progress should be appropriate for the specific curriculum and students the teacher teaches.

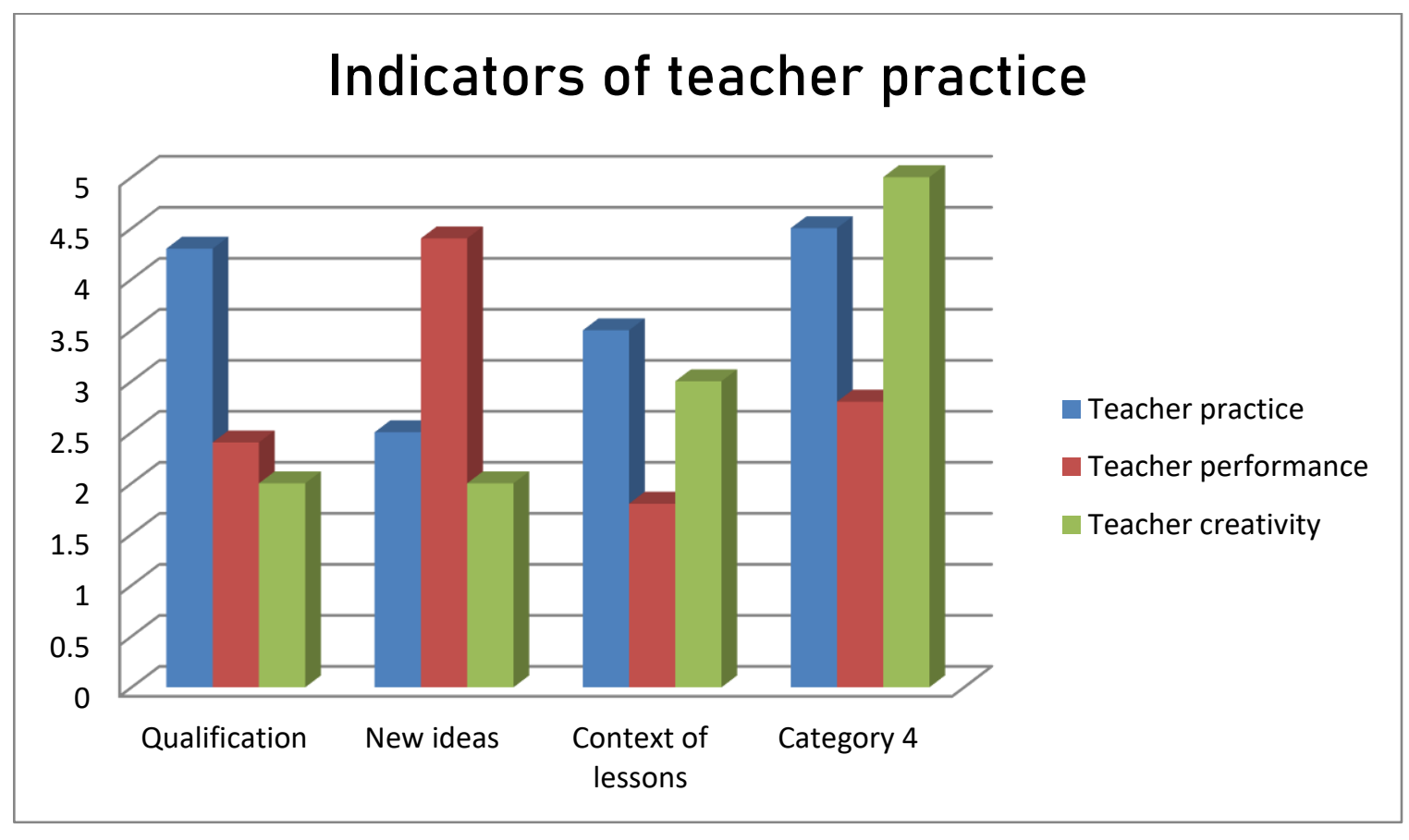

3. Evaluators should be knowledgeable about instruction and well trained in the evaluation system, including the process of how to give productive feedback and how to support ongoing learning for teachers.

As often as possible, and always at critical decision-making junctures (e.g., tenure or renewal), the evaluation team should include experts in the specific teaching field. Evaluation should be accompanied by useful feedback, and connected to professional development opportunities that are relevant to teachers' goals and needs, including both formal learning opportunities and peer collaboration, observation, and coaching.

\section{INTRODUCTION OF RESEARCH PAPER}

Such opportunities may include intensive institutes focused on particular strategies or on the teaching of specific curriculum, interspersed with opportunities for teachers to try things in the classroom, receive coaching, reflect 
ISSN 2661-2666 (Online) International Scientific Journal Monte (ISJM) DOI: 10.33807/monte/3/201912501 ISSN 2661-264X (Print)

together on their experiences, revise and revamp their approaches, and develop increasingly polished skills in an iterative cycle of practice, reflection, and fine-tuning.

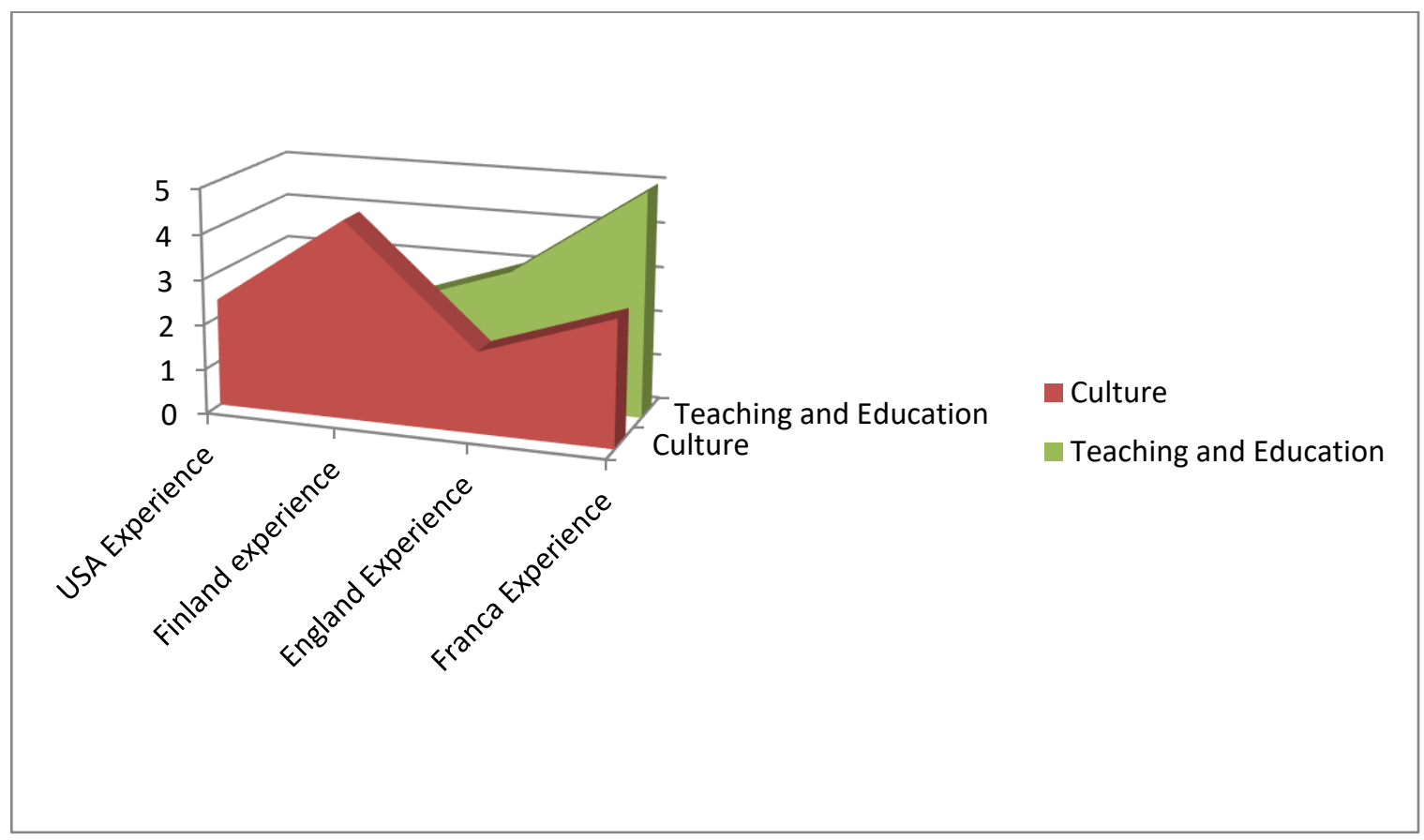

One problem identified is poor goal clarity because of a large number of criteria, which restricts teachers ${ }^{\text {ee }}$ understanding of the programmed and makes implementation difficult (Richardson, 1999). Explanations of how, and on what criteria, teachers are assessed may be difficult to articulate. When this occurs, it is almost impossible to give constructive feedback and maintain teacher support for the programmed (Chamberlin et al., 2002).

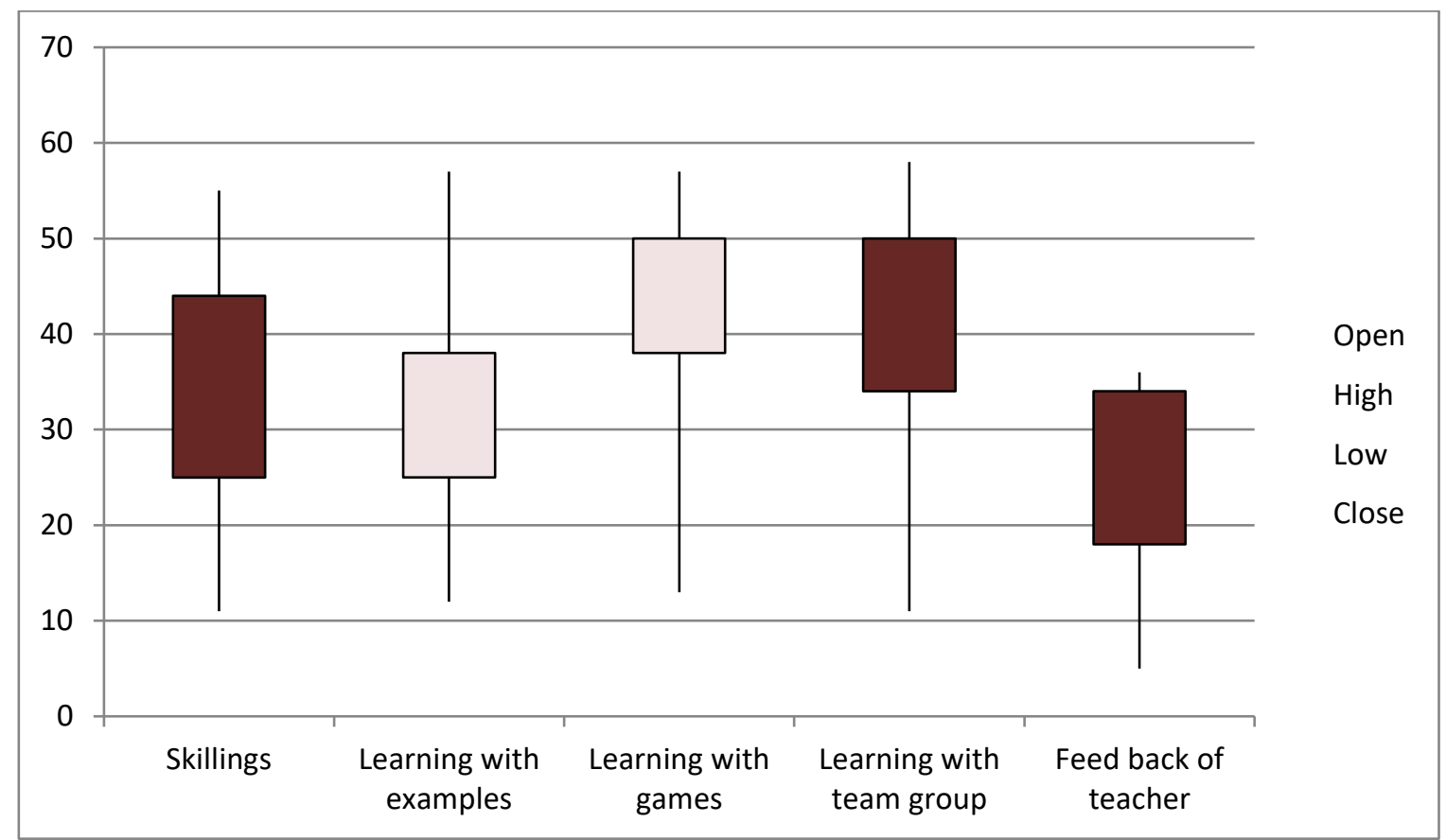


In addition, competencies for using feedback to improve practice are also vital to ensure that teacher evaluation procedures are effective. Teacher assessment for improvement is a key driver required in the process of school development. As a result, for instance, it is pertinent to include training for evaluation in initial teacher education alongside the development of research skills. Particular groups such as inspectorates are also in a good position to engage in modeling and disseminating good practice in teacher evaluation. It is also critical to ensure the availability of vast information and guidelines about teacher evaluation procedures to all involved in them.

Examples of school-level factors are: Socio-economic context of schools Management, leadership and distribution of responsibilities within school

\section{METHODOLOGY AND RESEARCH GOAL}

Teachers can benefit from training modules so they know what is expected from them to be recognized as ,,good ${ }^{\text {ee }}$ teachers, and to be prepared to make the best use of the feedback received. This contributes for teachers to appropriate the process through support and coaching. Evaluation and feedback ought also to be important aspects offered in initial teacher education and regular professional development activities.

These areas should receive priority for specialized training addressed to evaluators. Given their crucial pedagogical role, school directors should benefit from dedicated training. Offers targeted at school leaders typically focus on human resources development and school quality assurance, including school self-evaluation.

\section{LITERATURE AND REVIEW}

\section{Teachers and Professional Learning Opportunities}

Making the best use of teacher evaluation results raises a number of challenges such as feeding information on performance back to those who deliver educational services, most notably teachers and school principals; developing mechanisms for the improvement of teaching practices, notably teacher professional development; establishing rewards, support systems and consequences that flow from evaluation results; and developing the channels which ensure that information generated by teacher evaluation is used for educational policy development. These challenges highlight the importance of knowledge management in any teacher evaluation framework.

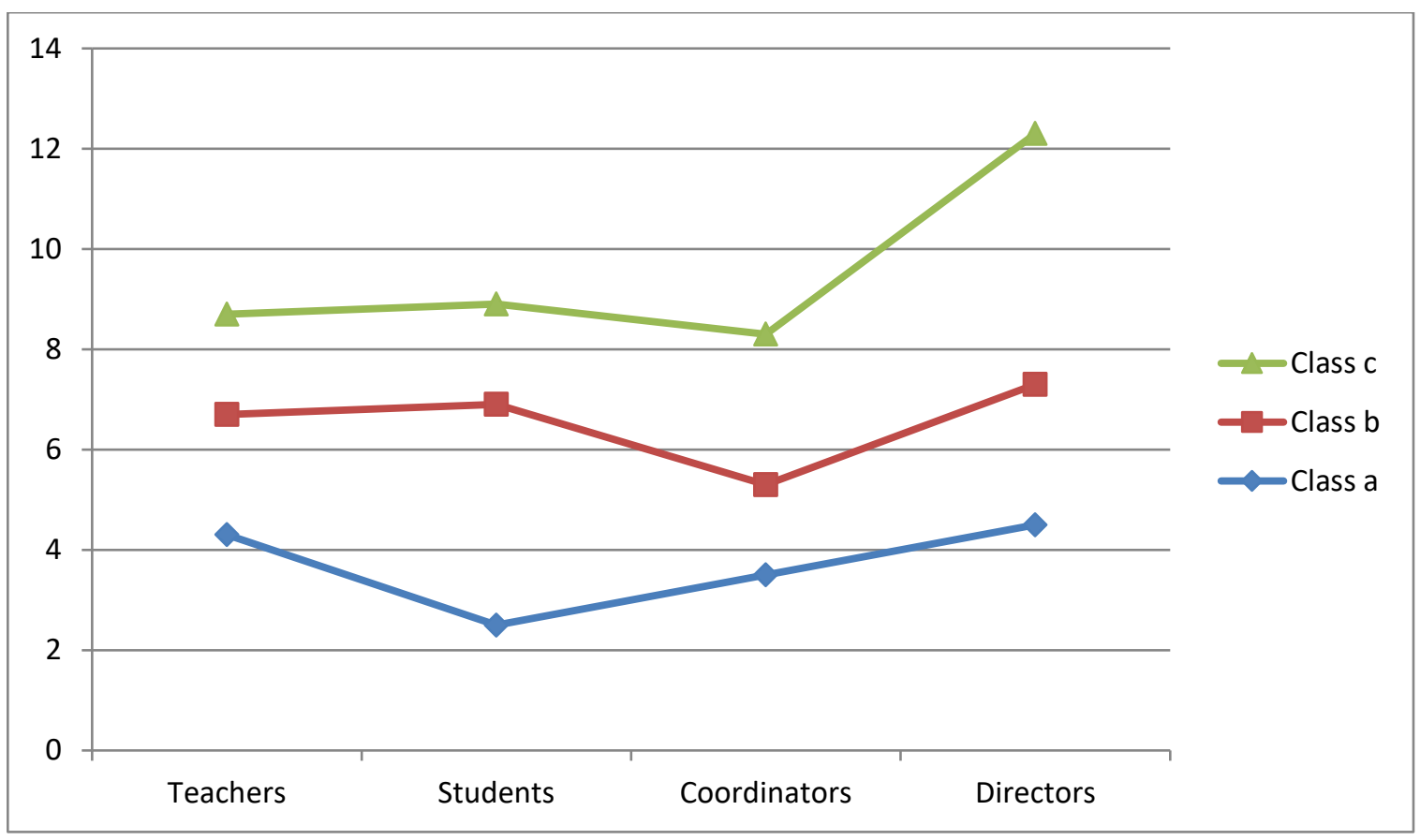




\section{CONCLUSIONS AND RECOMMENDATIONS}

Tasting from the next academic year, a new system of education and training for pre-school and early school education teachers will enter in force. Students who have already started their training are taught according to the previous rules.

Changes in the system of education and training of pre-school and early school education teachers will enter into force on 1 October 2019. Teacher education will be offered as part of a long-cycle master's degree programmed in preschool and early-school pedagogy.

\section{New education standards}

The changes will be introduced by the regulation of the Minister of Science and Higher Education on the standard of initial teacher education, which will enter in force on 1 October 2019. The amendment will apply only to those students who commence their studies in October - the remaining ones will continue their studies in accordance with existing rules.

Current (or previous) qualification system applies to students who graduated or commenced their studies before 1 October 2019. At present, graduates of first cycle programmers in pedagogy trained to work with children at the stage of preschool or early school education hold qualifications to teach pre-scholars and primary school grade 1-3 students. Teachers need feedback on their performance to help them identify how to better shape and improve their teaching practice and, with the support of effective school leadership, to develop schools as professional learning communities. At the same time, teachers should be accountable for their performance and progress in their careers on the basis of demonstrated effective teaching practice.

Developing a comprehensive approach may be costly but is critical to conciliate the demands for educational quality, the enhancement of teaching practices through professional development, and the recognition of teacher knowledge, skills and competencies. The expectation is that teachers engaging in reflective practice, studying their own methods of instruction and assessment, and sharing their experience with their peers in schools, becomes regular a routine part of professional life.

Other students who are mobile may have spent only a short time in a given teacher's classroom. Both of these are sources of considerable error. Year-to-year instability in teacher rankings is also very high. 
ISSN 2661-2666 (Online) International Scientific Journal Monte (ISJM) DOI: 10.33807/monte/3/201912501

ISSN 2661-264X (Print)

\section{REFERENCES}

Teaching Profession: a Review of the Literature", Research Papers in Education, 17(1), pp. 31-49. Danielson, C. (1996, 2007),

Enhancing Professional Practice: a Framework for Teaching, 1st and 2nd editions,

Association for Supervision and Curriculum Development (ASCD), Alexandria, Virginia. Danielson, C. (2001), "New Trends in Teacher Evaluation",

Educational Leadership, Vol. 58, No. 5, pp. 12-15.

Danielson, C. and T. McGreal (2000), Teacher Evaluation to Enhance Professional Practice, Association for Supervision and Curriculum Development (ASCD), Alexandria,

Virginia. Eurydice (2008), "Levels of autonomy and responsibility of teachers in Europe", European Commission, Brussels, Education DG. Harvey-Beavis, O. (2003), "Performance-Based Rewards for Teachers: A Literature Review", paper distributed at the third workshop of participating countries on OECD Activity "Attracting, Developing and Retaining Effective Teachers", 4-5 June, Athens, Greece.

Available from www.oecd.org/edu/teacherpolicy Heneman, H., A. Milanowski, S. Kimball and A. Odden (2006), “

Standards-Based Teacher Evaluation as a Foundation for Knowledge- and Skill-Based Pay”, Consortium for Policy Research in Education (CPRE) Policy Briefs RB-45.Cavaluzzo, L. (2004).

Is National Board Certification an effective signal of teacher quality? (National Science Foundation No. REC0107014). Alexandria, VA: The CNA Corporation; Goldhaber, D., \& Anthony, E. (2005).

Can teacher quality be effectively assessed? Seattle, WA: University of Washington and the Urban Institute; Smith, T., Gordon, B., Colby, S., \& Wang, J. (2005).

An examination of the relationship of the depth of student learning and National Board certification status. Boone, NC: Office for Research on Teaching, Appalachian State University; Vandevoort, L. G., Amrein-Beardsley, A., \& Berliner, D. C. (2004). National Board certified teachers and their students' achievement.

Education Policy Analysis Archives, 12(46), 117. 8 Athanases, S. (1994). Teachers' reports of the effects of preparing portfolios of literacy instruction.

Elementary School Journal, 94(4), 421-439. 9 Sato, M., Wei, R. C., \& Darling-Hammond, L. (2008). Improving teachers' assessment practices through professional development: The case of National Board Certification.

American Educational Research Journal, 45, 669-700; Tracz, S.M., Sienty, S. \& Mata, S. (1994, February).

The self-reflection of teachers compiling portfolios for National Certification: Work in progress. Paper presented at the Annual Meeting of the American

Association of Colleges for Teacher Education, Chicago, IL; Tracz, S. M., Sienty, S., Todorov, K., Snyder, J., Takashima, B., Pensabene, R., Olsen, B., Pauls, L.,

Accomplished California Teachers. (2010). A quality teacher in every classroom: Creating a teacher evaluation system that works for California. 
ISSN 2661-2666 (Online) International Scientific Journal Monte (ISJM) DOI: 10.33807/monte/3/201912501

ISSN 2661-264X (Print)

Stanford, CA: National Board Resource Center, Stanford University. 2 For a summary of studies, see DarlingHammond, L., \& Bransford, J. (2005).

Preparing teachers for a changing world: What teachers should learn and be able to do. San Francisco: JosseyBass; DarlingHammond, L. (2000). Teacher quality and student achievement: A review of state policy evidence.

Educational Policy Analysis Archives, 8(1). Retrieved from http://epaa.asu.edu/epaa/v8n1; Wilson, S. M., Floden, R., \& Ferrini-Mundy, J. (2001).

Teacher preparation research: Current knowledge, gaps, and recommendations. Seattle: Center for the Study of Teaching and Policy, University of Washington.

Clotfelter, C., Ladd, H., and Vigdor, J. (2007). How and why do teacher credentials matter for student achievement? (NBER Working Paper 12828).

Cambridge, MA: National Bureau of Economic Research; Goldhaber, D., \& Brewer, D. (2000). Does teacher certification matter? High school teacher certification status and student achievement. Educational evaluation and policy analysis, 22(2), 129-145. 4

Skinner, K. J. (2010). Reinventing evaluation: Connecting professional practice with student learning. Boston, MA: Massachusetts Teachers Association.

Milanowski, A., Kimball, S. M., \& White, B. (2004). The relationship between standards-based teacher evaluation scores and student achievement. University of Wisconsin-Madison, Consortium for Policy Research in Education. 15 Milanowski, Kimball, \& White, 2004.

Milanowski, Kimball, \& White, 2004. 17 Hassell, B. C. (2002). Better pay for better teaching: Making teacher compensation pay off in the age of accountability. Progressive Policy Institute 21st Century Schools Project. Retrieved November 18, 2004, from http://www.broadfoundation.org/investments/educationnet.shtml 18 Fryer, R. G. (2011). Teacher incentives and student achievement: Evidence from New York City Public Schools (NBER Working Paper no. 16850).

Cambridge, MA: National Bureau of Economic Research; Martins, P. (2009). Individual teacher incentives, student achievement and grade inflation (Discussion Paper No. 4051).

London, UK: Queen Mary, University of London, CEG-IST and IZA; Springer, M. G., Ballou, D., Hamilton, L., Le, V., Lockwood, J. R., McCaffrey, D. F., Pepper, M., and Stecher, B. M. (2010).

Teacher pay for performance: Experimental evidence from the Project on Incentives in Teaching. Nashville, TN: National Center on Performance Incentives, Vanderbilt University

National Association of State Boards of Education (NASBE) Study Group on Teacher Preparation, Retention, Evaluation, and Compensation (2011).

Gearing Up: Creating a Systemic Approach to Teacher Effectiveness. Arlington, 